\title{
A Review of Bending and Contact Stress Analysis of Helical Gear
}

\section{Authors}

Pravinkumar M Shah ${ }^{1}$, Mr. A. N. Surde ${ }^{2}$

${ }^{1}$ Department of Mechanical Engineering, Walchand Institute of Technology, Ashok Chowk, Solapur-413006

${ }^{2}$ Assistant Professor, Mechanical Engineering Department, Walchand Institute of Technology, Ashok Chowk, Solapur-413006.

Email: shahpravinkumar54@gmail.com

\section{ABSTRACT}

This paper reviews Bending and Contact Stress Analysis of Helical Gear. In this paper the bending stress and contact stress of the gear tooth are examined and are to be one of the main contributors for the failure of the gear in a gear set. Thus, the analysis of stresses has become popular as an area of research on gears to minimize or to reduce the failures and for optimal design of gears.

Keywords-Bending Stress, Contact Stress, Helix Angle, Face Width, AGMA

\section{INTRODUCTION}

A gear is a rotating machine part having cut teeth, which mesh with another toothed part in order to transmit torque. Two or more gears working on tandem are called a transmission and can produce a mechanical advantage through a gear ratio and thus may be considered a simple machine. Geared devices can change the speed, magnitude and direction of a power source. The gears in a transmission are analogous to the wheels in a pulley. An advantage of gears is that the teeth of a gear prevent slipping.

For transmitting power and motion from one shaft to another gear are used. Gears are mostly used to transmit torque and angular velocity. Helical gears are currently used as a power transmitting gear due to their relatively smooth and silent operation, large load carrying capacity and higher operating speed. Helical gears differ from spur gears both in geometry and working behavior. Spur gears commonly have a contact line axially aligned and the load is distributed evenly across the width of the gear tooth. However, it is not the case for helical gears. Helical gears have a smoother operation than the spur gears because of helix angle that increases the length of the contact lines. The difference in contact lines is shown in Figure 1.
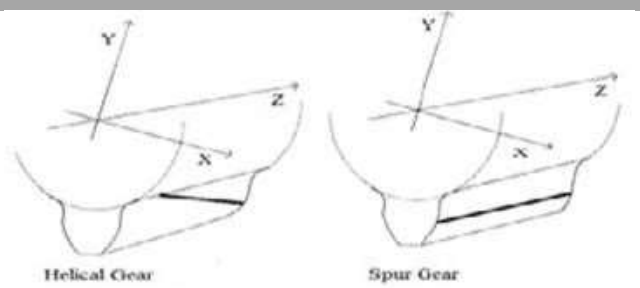

Figure 1. Line of contact along helical and spur gear[9]

In order to achieve high load carrying capacity with reduced weight of gear drives but with increased strength in gear transmission, gear design on the basis of tooth stress analysis, tooth modifications and optimum design of gear drives are becoming major research areas. Helical gears have more advantages than other gears especially spur gears like it has smoother engagement of teeth, silent in operation, can handle heavy loads and power can be transferred between non parallel shafts, high efficient etc. Due to these advantages it has wide range of applications in high speed high power mechanical systems.

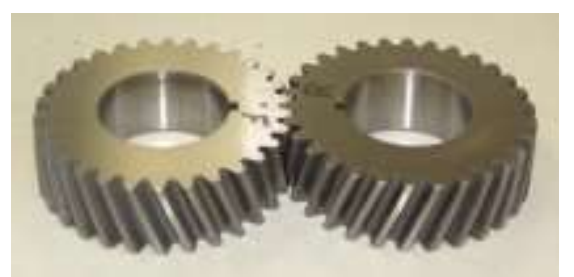

Figure 2. Helical Gear

The gear contact stress problem has been a great point of interest for many years, but still an extensive research is required to understand 
the various parameters affecting this stress. In the gear design the bending stress and surface strength of the gear tooth are considered to be one of the main contributors for the failure of the gear in a gear set. Thus, the analysis of stresses has become popular as an area of research on gears to minimize or to reduce the failures and for optimal design of gears.

\section{LITERATURE REVIEW}

A literature review is carried out in order to have a detailed knowhow of developments in the field of Bending and Contact Stress Analysis of Helical Gear.

J. Venkatesh \& Mr. P. B. G. S. N. Murthy [1] mentioned analytical and Finite Element Analysis methods that are used to predicting the Bending and Contact stresses of involute helical gear. Pro-e solid modeling software is used to generate the 3-D solid model of helical gear. Bending stresses are calculated by using modified Lewis beam strength equation and ANSYS software package. Contact stresses are calculated by using AGMA contact stress equation and ANSYS software package. Finally these two methods bending and contact stress results are compared with each other. Figure 3 shows solid model of helical gear generated by pro/engineer.

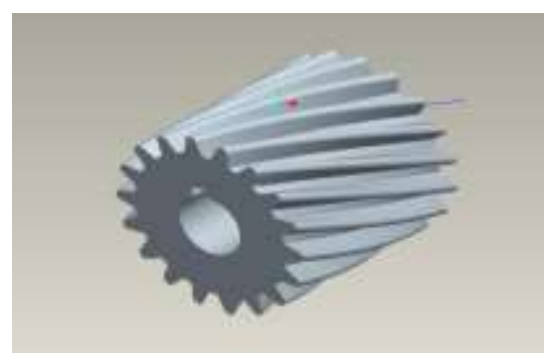

Figure 3. Solid model of Helical gear generated by PRO/ENGINEER [1]

Santosh S. Patil, Saravanan Karuppanan, Ivana Atanasovska, Azmi Abdul Wahab [2] presented the contact stresses among the helical gear pairs, under static conditions, by using a 3D finite element method. The helical gear pairs on which the analysis is carried are $0,5,15,25$ degree helical gear sets. The Lagrange multiplier algorithm has been used between the contacting pairs to determine the stresses. The helical gear contact stress is evaluated using FE model and results have also been found at different coefficient of friction, varying from 0.0 to 0.3 .

The FE results have been further compared with the analytical calculations. The analytical calculations are based upon Hertz and AGMA equations, which are modified to include helix angle. The commercial finite element software was used in the study and it was shown that this approach can be applied to gear design efficiently. The contact stress results have shown a decreasing trend, with increase in helix angle.

Figure 4 shows the contact stresses decreased with the helix angle for a constant coefficient of friction value and figure 5 shows the increase in contact stress with the increase in coefficient of friction.

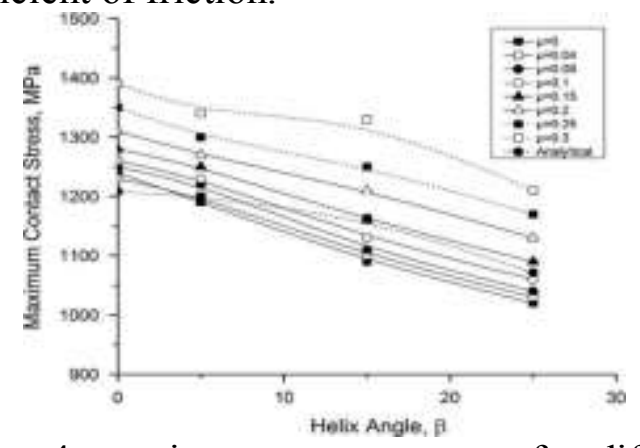

Figure 4. maximum contact stress for different helix angles [2]

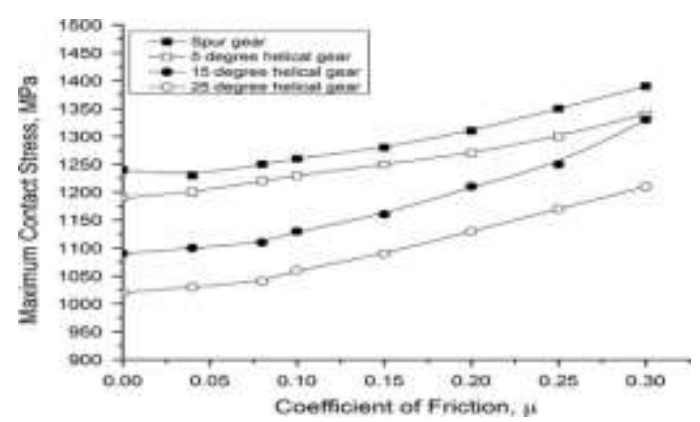

Figure 5. maximum contact stress for varying coefficient of friction [2]

S. Jyothirmai, R. Ramesh, T. Swarnalatha, D. Renuka [3] presented a comparative study on helical gear design and its performance based on various performance metrics through finite element as well as analytical approaches. The theoretical analysis for a single helical gear system based on American Gear Manufacturing Association (AGMA) standards has been assessed in Matlab. The effect of major performance metrics of different helical gear tooth systems such as single, herringbone 
and crossed helical gear are studied through finite element approach (FEA) in ANSYS and compared with theoretical analysis of helical gear pair. Structural, contact and fatigue analysis are also performed in order to investigate the performance metrics of different helical gear systems. The benefit of such a comparison is quickly estimating the stress distribution for a new design variant without carrying out complex theoretical analysis as well as the FEA analysis gives less scope for manual errors while calculating complex formulas related to theoretical analysis of gears. It will significantly reduce processing time as well as enhanced flexibility in the design performance. It was found that the overall performance of crossed helical gear was found to be the best in terms of stress as well as tooth strength at low loads whereas herringbone and single helical gear systems are employed for optimum values of speeds and loads. The tooth bending and fatigue stress distribution for single helical gear is shown in figure 6 and 7. The contact stress analysis for double helical gear is shown in figure 8 .

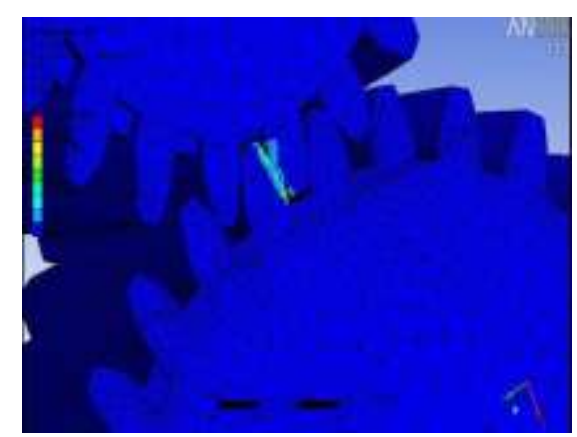

Figure 6. Tooth bending stress distribution for single helical gear [3]

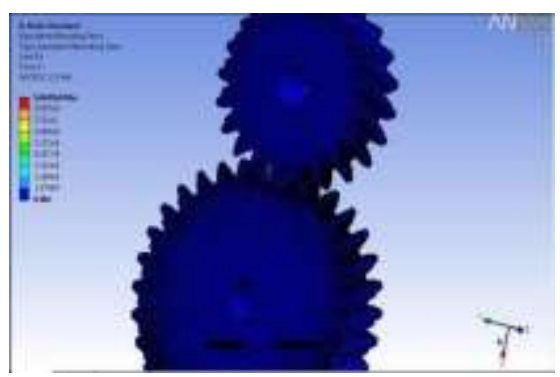

Figure 7. Fatigue stress distribution for single helical gear [3]

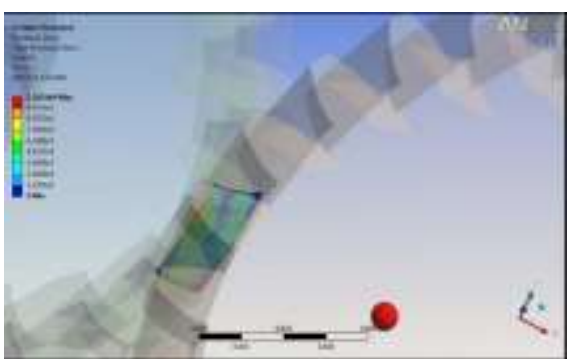

Figure 8. Contact stress analysis for double helical gear[3]

Tanvirkhan A. Malek [4] In this paper author have been presented a brief review of design and modeling and analysis of high speed helical gear using AGMA and ANSYS with various face width and helix angle and found their effect due to bending and contact stress and its value compared with ANSYS and AGMA.

S.Sai Anusha, P.Satish Reddy, P.Bhaskar, M Manoj [5] In this paper the bending stress and surface strength of the gear tooth are considered to be one of the main contributors for failure of the gears in gear set. The analysis of stresses has become popular as an area of research on gears to minimize and reduce the failures. The present investigation is carried out to make use of helical gear, by analyzing the contact stresses for different Pressure angles $\left(14.5^{\circ}, 16^{\circ}, 18^{\circ}, 20^{\circ}\right)$, Helix angles $\left(15^{\circ}, 20^{\circ}, 25^{\circ}, 30^{\circ}\right)$ and Face width $(80 \mathrm{~mm}, 90 \mathrm{~mm}, 100 \mathrm{~mm}, 110 \mathrm{~mm}, 120 \mathrm{~mm})$. A Three- dimensional solid model is generated by Pro-E which is powerful and modern solid modeling software. The numerical solution is done by ANSYS, which is a finite element analysis package. The analytical approach is based on contact stress equation, to determine the contact stresses between two mating gears. The results obtained from ANSYS values are compared with theoretical values are in close agreement.

B.Venkatesh, V.Kamala, A.M.K.Prasad [6] In this work, structural analysis on a high speed helical gear used in marine engines, have been carried out. The dimensions of the model have been arrived at by theoretical methods. The stresses generated and the deflections of the tooth have been analyzed for different materials. Finally the results obtained by theoretical analysis and Finite Element Analysis are compared to check the correctness. A conclusion has been arrived on the material which is best suited for the marine engines based on the 
results. Basically the project involves the design, modeling and manufacturing of helical gears in marine applications. It is proposed to focus on reduction of weight and producing high accuracy gears.

BabitaVishwakarma, Upendra Kumar Joshi [7] This paper investigates finite element model for monitoring the stresses induced of tooth flank, tooth fillet during meshing of gears. The involute profile of helical gear has been modeled and the simulation is carried out for the bending and contact stresses and the same have been estimated. To estimate bending and contact stresses, 3D models are generated by modeling software CATIA V5 and simulation is done by finite element software package ANSYS 14.0. Analytical method of calculating gear bending stresses uses Lewis and AGMA bending equation. For contact stresses Hertz and AGMA contact equation are used. Study is conducted by varying the face width to find its effect on the bending stress of helical gear. It is therefore observed that the maximum bending stress decreases with increasing face width. The stresses found from ANSYS results are compared with those from theoretical and AGMA values.

Yi-Cheng Chen, Chung-Biau Tsay [8] Evaluated the contact stress and bending stress of a helical gear set with localized bearing contact, by means of finite element analysis (FEA). The proposed helical gear set comprises an involute pinion and a double crowned gear. Mathematical models of the complete tooth geometry of the pinion and the gear have been derived based on the theory of gearing. Accordingly, a mesh- generation program was also developed for finite element stress analysis. The gear stress distribution is investigated using the commercial FEA package, ABAQUS/Standard.

Santosh Patil, Saravanan Karuppana, Ivana Atanasovska, Azmi A. Wahab and M. R. Lias [9] This paper represent the study of contact stresses among the helical gear pairs, under static conditions, by using a 3D finite element method. The helical gear pairs on which the analysis is carried are $0,5,15,25$ degree helical gear sets. The FE results have been further compared with the analytical calculations. The analytical calculations are based upon Hertz and AGMA equations, which are modified to include helix angle. The contact stress results have shown a decreasing trend, with increase in helix angle.

Summary of Literature Review

To minimize or to reduce the failures and for optimal design of gears, analysis of stresses become popular as an area of research. From the above literature review, the bending stress and contact stress of the gear tooth are examined. Most of the researchers used AGMA equations for finding the bending and contact stresses theoretically and ANSYS software package for their analysis purpose. Analysis results are compared with analytical one.

Findings on Literature Review

The extensive research in the field of stress analysis of helical gear is going on.

Many researchers reported study on contact stress of helical gear for specific helix angle (i.e.0 , $5,15,25,30$ only).

PRO-E \& ANSYS software's are used for analysis purpose.

\section{CONCLUSION}

From this review of research on Bending and Contact Stress Analysis of Helical Gear we can conclude that

This paper presented a brief review of bending and contact stress analysis of helical gear using AGMA and ANSYS with various face width and helix angle.

It is found that the as helix angle increases the contact stress decreases. That is contact stresses are inversely proportional with the helix angle.

Helix angle is important geometrical parameter in determining the state of stressesduring the design of the gear.

\section{REFERENCES}

1. J. Venkatesh, Mr. P. B. G. S. N. Murthy, "Design and Structural Analysis of High Speed Helical Gear Using Ansys", Int. Journal of Engineering Research and Applications, Vol. 4, Issue 3 (Version 2), pp.01-05,(2014).

2. Santosh,S.Patil,Saravanan Karuppanan, IvanaAtanasovska, Azmi Abdul Wahab, "Contact stress analysis of helical gear pairs, including frictional 
coefficients", International Journal of Mechanical Sciences, pp.205-211, (2014).

3. S. Jyothirmai, R. Ramesh, T. Swarnalatha, D. Renuka, "A Finite Element Approach to Bending, Contact and Fatigue Stress

Distribution in Helical Gear Systems", 3rd International Conference on Materials Processing and Characterisation, pp.907- 918, (ICMPC 2014).

4. TanvirkhanA.Malek, “A Review: Design, Modeling and Stress Analysis of high speed helical gear according to Bending strength and Contact strength using AGMA and ANSYS", International Journal of Engineering Trends and Technology (IJETT) Volume 22,(2015).

5. S.SaiAnusha, P.Satish Reddy, P.Bhaskar, M Manoj, "Contact Stress Analysis of Helical Gear by Using AGMA and ANSYS", International Journal of Science Engineering and Advance Technology, Vol.2, Issue 12, (2014).
6. B.Venkatesh, V.Kamala, A.M.K.Prasad, "Design, Modelling and Manufacturing of Helical Gear", International Journal of Applied Engineering Research, Dindigul Volume 1, No1, (2010).

7. BabitaVishwakarma, Upendra Kumar Joshi, "Finite Element Analysis of Helical Gear Using Three- Dimensional Cad Model", International Journal of Engineering Sciences \& Research Technology (2014).

8. Yi-Cheng Chen, Chung-BiauTsay, "Stress analysis of a helical gear set with localized bearing contact", Finite Elements in Analysis and Design 38, pp707-723,(2002).

9. Santosh Patil, Saravanan Karuppana, Ivana Atanasovska, Azmi A. Wahab and M. R. Lias, "Contact Stress Analysis for Gearsof Different Helix Angle Using Finite Element Method", MATEC Web of Conferences 13,04023 pp.01-05, (2014) 